\title{
Controlling photo-oxidation processes of a polyfluorene derivative: The effect of additives and mechanism
}

\author{
G.R. Ferreira ${ }^{\text {a }}$, B. Nowacki ${ }^{\mathrm{b}}$, A. Magalhães ${ }^{\mathrm{c}}$, E.R. deAzevedo ${ }^{\mathrm{d}}$, E.L. de Sá ${ }^{\mathrm{e}}$, L.C. Akcelrud ${ }^{\mathrm{b}}$, \\ R.F. Bianchi ${ }^{a, *}$
}

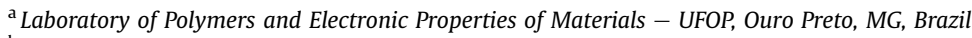

${ }^{\mathrm{b}}$ Paulo Scarpa Polymer Laboratory - UFPR, Curitiba, PR, Brazil

${ }^{\mathrm{C}}$ Instituto de Química, Universidade Estadual de Campinas - UNICAMP, Campinas, SP, Brazil

${ }^{\mathrm{d}}$ Instituto de Física de São Carlos, Universidade de São Paulo - USP, São Carlos, SP, Brazil

${ }^{\mathrm{e}}$ Chemistry Department, Federal University of Parana, Curitiba, PR, Brazil

\section{H I G H L I G H T S}

- Photo degradation control of a fluorene-vinylene-phenylene based polymer was achieved.

- A radical scavenger enhanced photo resistance and radical initiator decreased it.

- Color change rate with irradiation dose provided a basis for dosimeter construction.

\section{A R T I C L E I N F O}

\section{Article history:}

Received 11 July 2013

Received in revised form

6 February 2014

Accepted 23 February 2014

\section{Keywords:}

Optical properties

Oxidation

Radiation damage

Electronic materials

\begin{abstract}
A B S T R A C T
The control of the photo degradation of a fluorene-vinylene-phenylene based-polymer, poly(9,9-dihexylfluorenediylvinylene-alt-1,4-phenylenevinylene) (LaPPS16) was achieved by addition of a radical scavenger (RS) (enhancing photo resistance) or a radical initiator (RI) (reducing photo resistance). Photoluminescence, UV-Vis absorption, ${ }^{1} \mathrm{H}$ NMR spectroscopies and gel permeation chromatography (GPC) revealed that the incorporating small amounts of RS or RI is an efficient way to control the rates of the photo-oxidation reactions, and thus to obtain the conjugated polymer with foreseeable degradation rates for applications in blue-light sensitive detectors for neonatal phototherapy.
\end{abstract}

(c) 2014 Elsevier B.V. All rights reserved.

\section{Introduction}

Since the discovery of semiconducting properties of conjugated polymers [1,2], the electronic properties of poly( $p$-phenylenevinylene)s (PPVs) and polyfluorenes (PFs) have attracted considerable attention due to their promising applications as active layers in several optoelectronic devices as solar cells [3], displays [4] and transistors [5], among others. The good features of PPVs and PFs include low-cost, low weight, easy processing and solubility in common organic solvents [6]. However, low durability still remains as a challenge in technological applications. Despite the various

\footnotetext{
* Corresponding author. Department of Physics, Federal University of Ouro Preto, Campus Morro do Cruzeiro, 35400000 Ouro Preto, MG, Brazil. Tel.: +55 (31) 35591742.

E-mail addresses: bianchi@iceb.ufop.br, rfbufop@gmail.com (R.F. Bianchi).
}

advantages and applicability of these polymers, it is important to note that the high absorption of visible radiation coupled with the presence of conjugated system makes them susceptible to photochemical reactions. The photo-oxidation process of poly- $p$-vinylene phenylene derivatives causes changes in their optical properties due the oxidation of vinyl group by carbonyl groups and reduction on the effective conjugation lengths [7-13]. Photo-oxidation of polyfluorenes chains results in ketonic defects (fluorenone groups) which quenches the fluorescence. A second process has been identified, it promotes aggregate formation, which then leads to loss of luminous intensity [14-20]. These processes have deleterious effects on both efficiency and performance of the electronic devices based on these materials. On the other hand, the change of color induced by radiation has been recently explored in the fabrication of light dosimeters since a relationship between the light intensity that reaches the sample and the color change can be established [21-24]. Recently, some works have been showed the 
development of radiation sensor evaluation based on conjugated polymers to monitoring ionizing or non-ionizing radiation to use in neonatal phototherapy [21,22], radiotherapy using X-rays [23] or gamma radiation [24]. The operating principle of the device is based on the change of optical properties of solutions and films promoted by photo-oxidation process of luminescent polymers. Furthermore, the sensor present advantages such as easy to make, easy to read, easy to operate, low-cost and accuracy for person monitoring to represent easily the dose of radiation exposure [21-24].

In this sense, apart from the pure physical chemical interest will help to elucidate the photo-degradation process in conjugated polymers, the control of reaction rate is important to improve organic electronic devices stability and to adjust the doseresponse curves of radiation sensors. The radical nature of polymer photo-degradation is well established and the use of radical scavengers is a widespread means to improve plastics stability [25]. At the same time free radical forming compounds such as peroxides, which have been used as polymerization initiator, are able to react with double bonds giving rise to degradation initiation and propagation reactions. These two processes polymer degradation and polymer protection, by the use of the adequate agents, can be explored to control the color change in emitting polymers. Nevertheless one requirement needs to be fulfilled: the additive, light radical scavenger or radical initiator, cannot interfere with the electronic absorption or emitting spectra of the polymer. In this contribution the long established concepts of radical scavenging or initiating is applied to luminescent polymers, in an attempt to contribute to the fabrication of light dosimeters. One example is the measure of the light dosage in blue-light phototherapy of jaundice neonates $[21,22]$.

In this contribution the photo-oxidation resistance or degradation of a highly light-emitting polyfluorene derivative, poly(9,9-dihexylfluorenediylvinylene-alt-1,4-fenilenovinylene) (LaPPS16), was studied by the addition of a hindered phenol as radical scavenger or benzoyl peroxide as a free radical initiator. The results obtained from solution would lead to a better understanding of the degradation process and would hopefully allow thin-film devices to be made, having in mind the measurement of the radiation dose around the patient.

\section{Materials and methods}

\subsection{Materials}

LaPPS16 was prepared as described in ref. [26], the radical scavenger (RS) was pentaerythritol tetrakis(3-(3,5-di-tert-butyl-4hydroxyphenyl)propionate) (Irganox $1010^{\circledR}$ ) and radical initiator (RI) (benzoyl peroxide) were purchased from Ciba Specialty Chemical Corporation and Sigma Aldrich, respectively.

\subsection{Procedures}

Solutions of LaPPS16, LaPPS16:RS and LaPPS16:RI were prepared by adding the additives to a polymer solution in chloroform at a concentration of $100 \mathrm{mg} \mathrm{L}^{-1}$. The solutions were transferred to glass ampoules that were then flame-sealed. The main specifications for ampoules were: nominal volume $=2 \mathrm{ml}$, external thickness $=10.75 \mathrm{~mm}$, and wall thickness $=0.50 \mathrm{~mm}$. Radiation exposure was performed by illuminating the solutions with blueLEDs ( $40 \mu \mathrm{W} \mathrm{cm}{ }^{-2}$ at $460 \mathrm{~nm}$ ), which corresponds to the absorption region of LaPPS16 [27]. All samples were kept at same distance from the radiation source in order to ensure the same blue light input. In fact, blue-light irradiation was performed at $30 \mathrm{~cm}$ from the samples to simulate the usual conditions used in the phototherapy of jaundice neonates [21,22].

Additionally, a Lasercheck current model 1098293 was used in order to check the radiance on the samples. The fluorescence (PL) spectra were recorded with an USB2000 Ocean Optics spectrophotometer and a blue $\operatorname{LED}\left(0.15 \mu \mathrm{W} \mathrm{cm}{ }^{-2}\right.$ at $\left.460 \mathrm{~nm}\right)$ as excitation source. The low central peak irradiance of the blue LED and the short measuring period ( $<1 \mathrm{~s}$ ) assured that photo-oxidation during the PL measurements was negligible. UV-Vis absorption (ABS) spectra were collected with Shimadzu UV 1650 equipment. The changes in chemical structure and in the chain length were monitored and the products analyzed by $1 \mathrm{H}$ NMR spectroscopy with a $300 \mathrm{MHz}$ Bruker AVANCEIII spectrometer. The samples were solved in $\mathrm{CDCl}_{3}$, sealed in $5 \mathrm{~mm}$ NMR tubes in air. Periods of blue light irradiation were intercalated with NMR measurement, so that, for a given sample, all the 1H NMR spectra were acquired in the same sample. Gel Permeation Chromatography was performed using an Agilent 1100 equipment.

\section{Results and discussion}

Fig. 1 shows the ABS and PL spectra of freshly made LAPPS16 solution in $\mathrm{CHCl}_{3}$ (Fig. 1(a)), and of the same solution after the addition of RS (Fig. 1(b)) and RI (Fig. 1(c)). No significant differences in the line shape of ABS and PL curves were observed with the presence of the additives. This was of prime importance to elucidate the role of the radical scavenger and initiator in the photo-oxidation process of fluorene-vinylene-phenylene basedpolymer, since it proved that the additives had no effect in the electronic structure of the pristine LaPPS16. The ABS and PL spectra

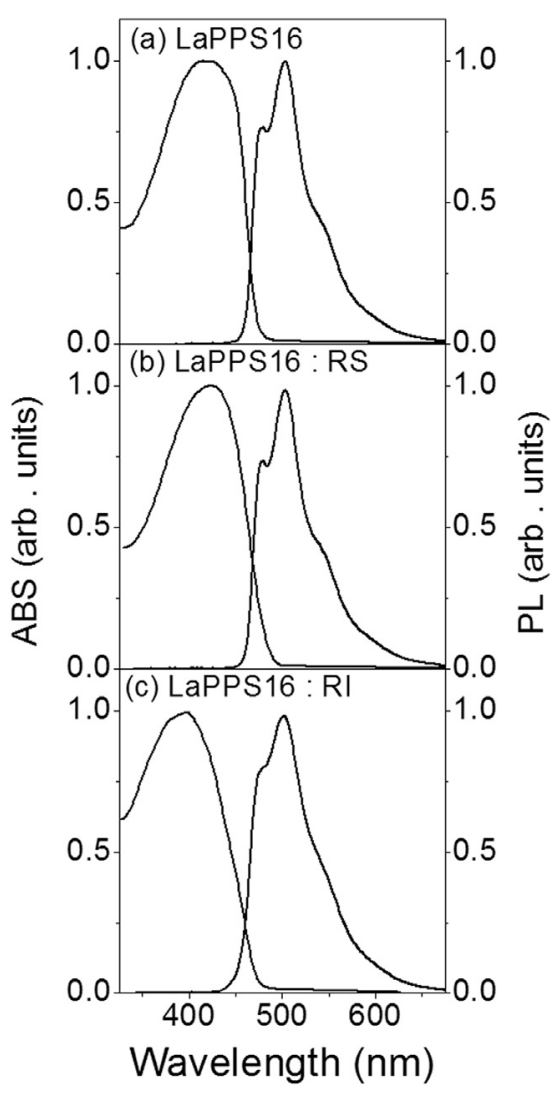

Fig. 1. UV-VIS absorption (ABS) and photoluminescence (PL) spectra of freshly made LaPPS16 solution in (a) pure $\mathrm{CHCl}_{3}$, (b) $\mathrm{CHCl}_{3}$ containing radical scavenger and (c) $\mathrm{CHCl}_{3}$ containing benzoyl peroxide. 
of LaPPS16, LaPPS16:RS and LaPPS16:RI solutions after exposure to the irradiation from a blue $\operatorname{LED}\left(40 \mu \mathrm{W} \mathrm{cm}{ }^{-2}\right)$ for $8 \mathrm{~h}$, are shown in Fig. 2. The effect of blue-light irradiation on the of ABS and PL intensities are depicted in Fig. 3. PL measurements were run with excitation wavelengths of $420 \mathrm{~nm}$ and $550 \mathrm{~nm}$ for the same period of time, it was observed that the LaPPS16:RI solution turned almost completely colorless.

The intensities of UV-Vis absorption at $420 \mathrm{~nm}$ and PL at $505 \mathrm{~nm}$ for LaPPS16 solutions without additives decrease slower than those observed for LaPPS16:RI, and faster than those observed for LaPPS16:RS. Indeed, considerable changes in the spectral intensities were observed when the LaPPS16 was in the presence of the radical initiator. Fig. 4 confirms the observed effect. It shows the color and emission of LaPPS16:RI, LaPPS16 and LaPPS16:RS solutions before (Fig. 4(a)) and after (Fig. 4(b)) exposure to $8 \mathrm{~h}$ of bluelight. It is clear from these figures that the color and emission of LaPPS16 solutions change drastically with radiation exposure, and the magnitude of these changes was affected by the rate of free radical formation. These results suggest that changes in effective conjugation length and/or scission of the polymer chain take place with the participation of free radicals [28].

The aforementioned modifications of the optical properties of LaPPS16 upon irradiation are associated with modifications in the chemical structure of the polymer. Thus, ${ }^{1} \mathrm{H}$ NMR experiments were performed for both pristine and irradiated polymer solutions. The ${ }^{1}$ H NMR spectrum of LaPPS16 is presented in Fig. 5 with the main lines identified according to the numbered chemical structure shown as inset. Although high resolution spectra could not be observed in this magnetic field, it was possible to identify distinct signals from alkyl and aromatic groups. For those the resonance

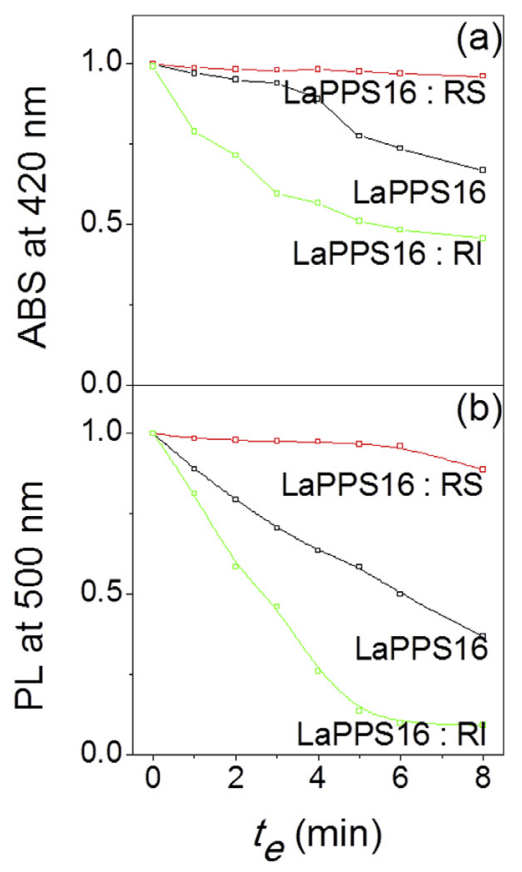

Fig. 3. Normalized $A B S$ at $420 \mathrm{~nm}$ (a) and PL intensities at $500 \mathrm{~nm}$ (b) of LaPPS 16 solutions in $\mathrm{CHCl}_{3}, \mathrm{CHCl}_{3}$ containing radical scavenger and $\mathrm{CHCl}_{3}$ containing benzoyl peroxide as function of radiation exposure time $\left(t_{\mathrm{e}}\right)$ Data taken from the experimental results shown in Fig. 2.

(a) before
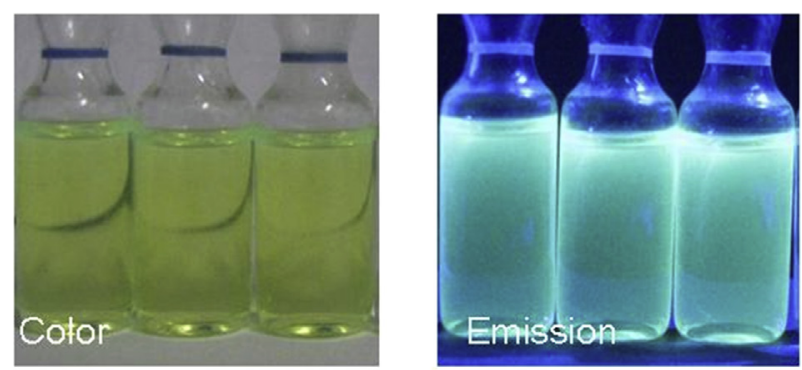

(b) after
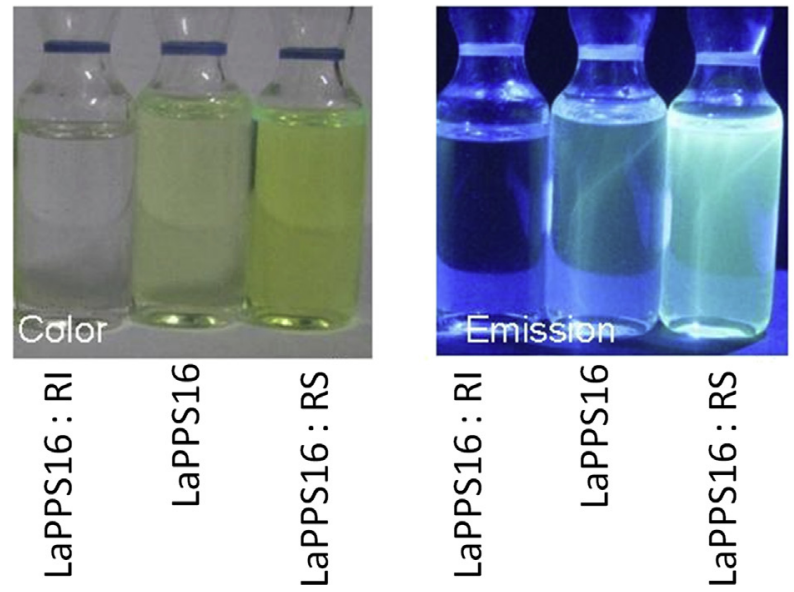

Fig. 4. Color of solutions in (1) LaPPS16:RI (2) LaPPS16 (3) LaPPS16:RS (a) before and (b) after radiation exposure to blue-light for $8 \mathrm{~h}$.
Fig. 2. Effect of blue-light $\left(40 \mu \mathrm{W} \mathrm{cm} \mathrm{cm}^{-2}\right.$ at $\left.460 \mathrm{~nm}\right)$ exposure time $\left(t_{\mathrm{e}}\right)$ on the ABS and $\mathrm{PL}$ spectra of LaPPS16 solutions in (a) $\mathrm{CHCl}_{3}$, (b) $\mathrm{CHCl}_{3}$ containing radical scavenger and (c) $\mathrm{CHCl}_{3}$ containing benzoyl peroxyde. 


\section{(a) $\times 8$}

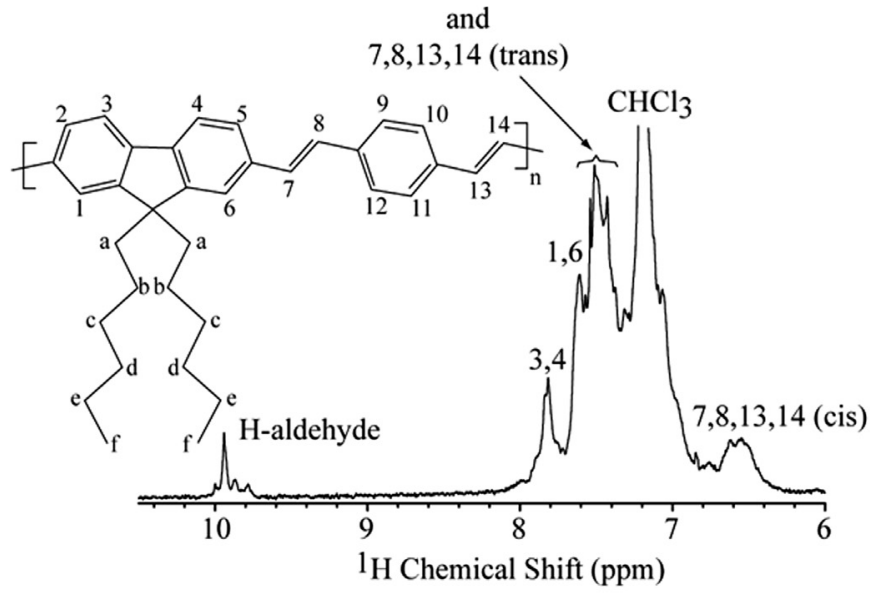

(b)

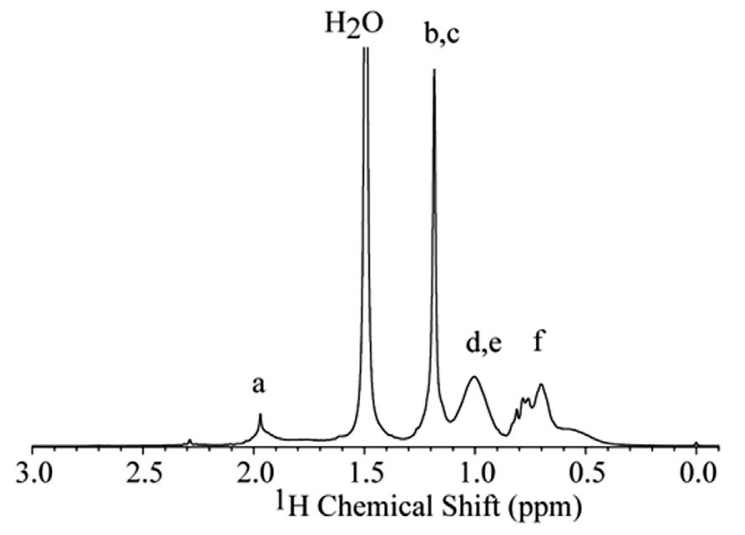

Fig. 5. ${ }^{1} \mathrm{H}$ NMR spectra of (a) main chain and (b) pedant groups of pristine LaPPS16 solutions in d-chloroform. As an inset the chemical structure of LaPPS16 with the ${ }^{1} \mathrm{H}$ numbered according to the NMR spectra.

assignments were: $10.05 \mathrm{ppm}-{ }^{1} \mathrm{H}$ from $\mathrm{H}$ on end chain aldehydes; $7.81 \mathrm{ppm}-{ }^{1} \mathrm{H} 3,4$ in fluorene rings; $7.61 \mathrm{ppm}-{ }^{1} \mathrm{H} \mathrm{1,6}$ in fluorene rings; 7.35-7.55 ppm $-{ }^{1} \mathrm{H} 9,10,11,12$ in phenylene rings and ${ }^{1} \mathrm{H} 7$, $6,13,14$ trans-vinylene groups; 7.35 ppm ${ }^{1} \mathrm{H} 2,5$ in fluorene rings; 6; 6 ppm - ${ }^{1} \mathrm{H} \mathrm{7,} \mathrm{6,13,14} \mathrm{cis-vinylene} \mathrm{groups.}$

Fig. 6 shows the LaPPS16 ${ }^{1} \mathrm{H}$ NMR spectra obtained for samples exposed to blue-light irradiation for $0,1,3,4,6,7$ and $9 \mathrm{~h}$. In the 6.0-10.5 ppm region (Fig. 6(a)), the main changes observed in the spectra upon irradiation are the disappearing of the signals at

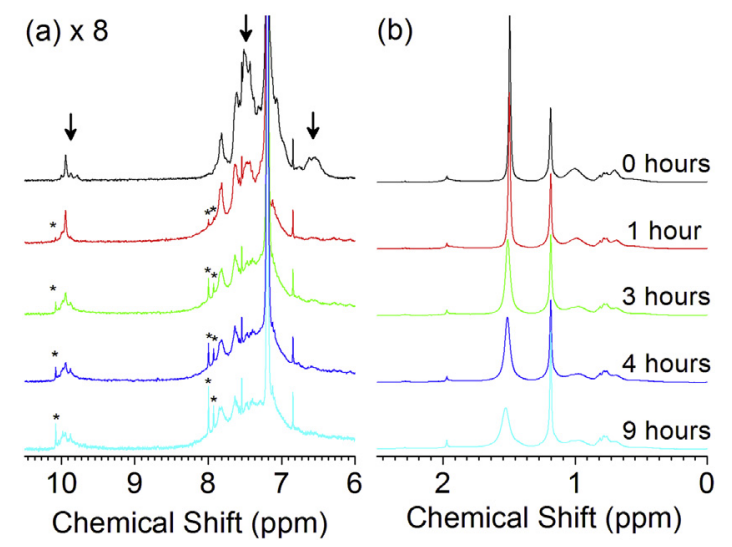

Fig. 6. ${ }^{1} \mathrm{H}$ NMR spectra of (a) main chain and (b) pedant groups of LaPPS16 solutions in d-chloroform exposed to blue radiation up to $540 \mathrm{~min}$.

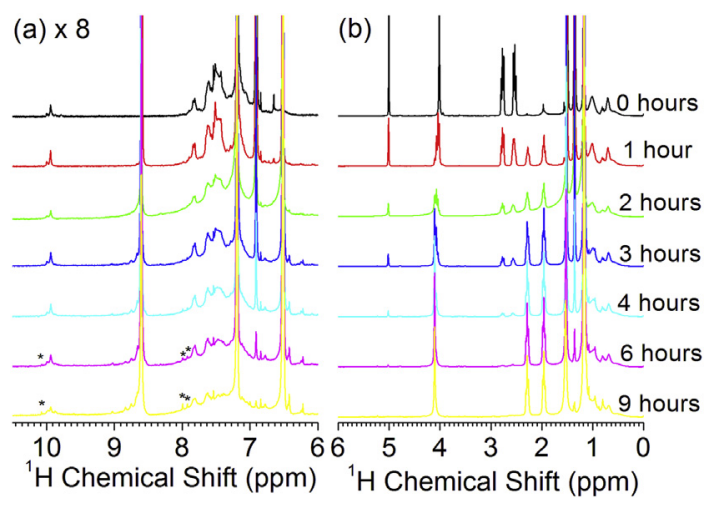

Fig. 7. ${ }^{1} \mathrm{H}$ NMR spectra of (a) main chain and (b) pedant groups of LaPPS16 solutions in d-chloroform with radical scavenger exposed to blue radiation up to $540 \mathrm{~min}$.

$\sim 6.5 \mathrm{ppm}$, the progressive reduction of the signals at $\sim 7.6 \mathrm{ppm}$ and the modification of the lines pattern at $\sim 10 \mathrm{ppm}$, indicated with arrows in Fig. 7. It is noteworthy that after $1 \mathrm{~h}$ of irradiation, the lines at $\sim 6.5 \mathrm{ppm}$ are absent, while the line at $\sim 7.6 \mathrm{ppm}$ still remains, disappearing in the spectrum corresponding to $3 \mathrm{~h}$ of irradiation. This suggests that cis-vinylene groups are more prone to oxidation than trans-vinylene groups. In contrast, the signals attributed to the aromatic groups do not show appreciate change with the blue-light exposure. Besides these major changes observed in this region spectrum upon blue-light irradiation, some sharp lines, indicated with asterisks, also appear, indicating the presence of small molecules in the irradiated samples. In the 0$2.5 \mathrm{ppm}$ region (Fig. 6(b)), there are no significant changes in the signal attributed to the ${ }^{1} \mathrm{H} \mathrm{a}, \mathrm{b}, \mathrm{c}, \mathrm{d}$ and e, but the signal arising from water traces in the sample is clearly broadened upon irradiation. This broadening indicates a reduction in the transversal relaxation time of the water molecules, which may be associated with the presence of unpaired electrons in free radicals in the solution. Notice that since all measurements were performed in the same sample, which was sealed to prevent evaporation and successively submitted to blue-light irradiation (no significant variation occurred in the sample volume), is very unlikely that this broadening is due to an increase in the solution concentration.

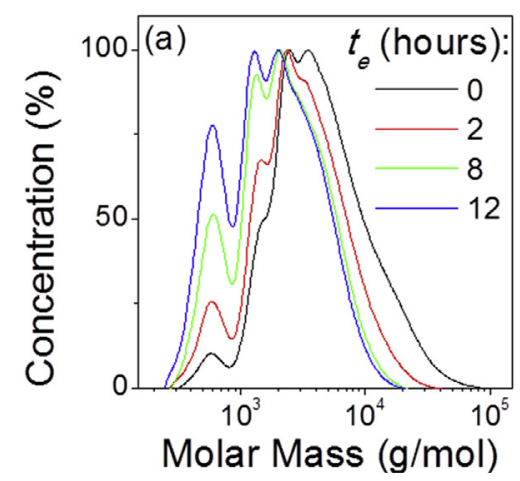

(b)

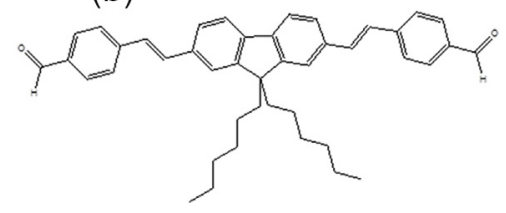

Fig. 8. (a) Gel permeation chromatograms of LaPPS16 exposed to blue radiation and (b) polymer fragment with molar mass corresponding to the first peak in the chromatogram. 
Table 1

$\mathrm{Mn}, \mathrm{Mw}, \mathrm{Mz}$ and polydispersity values of LaPPS 16 in function of radiation exposure time.

\begin{tabular}{lllll}
\hline$t_{\mathrm{e}} /$ hours & $\mathrm{Mn} / \mathrm{g} \mathrm{mol}^{-1}$ & $\mathrm{Mz} / \mathrm{g} \mathrm{mol}^{-1}$ & $\mathrm{Mw} / \mathrm{g} \mathrm{mol}^{-1}$ & Polydisper \\
\hline 0 & 2.939 & 14.290 & 6.337 & 2.156 \\
2 & 2.010 & 7.305 & 3.987 & 1.984 \\
8 & 1.495 & 4.880 & 2.837 & 1.898 \\
12 & 1.240 & 4.375 & 2.443 & 1.971 \\
\hline
\end{tabular}

Fig. 7 shows the ${ }^{1} \mathrm{H}$ NMR spectra obtained for LaPPS16 in a $\mathrm{CDCl}_{3}$ solution with the same concentration as those used for obtaining the spectra of Fig. 6, but with the addition of RS. The extra lines observed in Fig. 7 are due to the radical scavenger. As it can be noticed in Fig. 7(a), up to $4 \mathrm{~h}$ of exposure no significant change was observed in the lines attributed to the trans-vinylene groups. From 4 to $6 \mathrm{~h}$, the vinylene lines decrease and with $9 \mathrm{~h}$ of exposure the spectra become similar to that of the sample without the RS submitted to the same exposure to blue light, bottom spectra of Fig. 6(a). Indeed, the modification of the chemical structure of the scavenger due to reaction with free radicals induced by the bluelight irradiation is also observed in the $0-6 \mathrm{ppm}$ spectral region, Fig. 7(b). The lines attributed to the scavenger undergo noticeable changes with the exposure time. The most significant changes occur between 0 and $4 \mathrm{~h}$ of exposure, with the appearance and disappearance of new lines multiplets. For exposure times higher than $4 \mathrm{~h}$, the modification in the ${ }^{1} \mathrm{H}$ lines of the scavenger become subtler, showing that its activity is decreased. Put together, these results show that the presence of the radical scavenger inhibits the degradation of the LaPPS16 induced by the blue-light exposure.

In Figs. 6 and 7 it was observed that some narrow lines (marked with asterisks) appeared the degraded samples spectra. As mentioned, this is an indication that smaller molecules are formed. In order to evaluate this effect, gel permeation chromatograms of LaPPS16 exposed to blue radiation were run and depicted in Fig. 8. The number average $\left(M_{\mathrm{n}}\right)$, the weight average $\left(M_{\mathrm{w}}\right)$ and the $\mathrm{z}$ average $\left(M_{\mathrm{z}}\right)$ molecular weights of the pristine polymer were determined to be 3000, 6350 and 14300 (with polydispersity index of 2.15). After radiation exposure the values were 1240, 2440 and 4400 respectively (with polydispersity index of 1.97 ) using polystyrene as a standard (Table 1 ). It is noteworthy that the peak relative to molar mass 595 maintains its position throughout the runs, with progressive increasing intensity, as shown in Fig. 8, indicating that there is a preferential degradation locus. The probable structure with molar mass of 594 is shown in this figure.

Although we assume that the low molecular weight portion is related to a product of photo degradation process, this peak is already present in the pristine LaPPS16. In this sense, it is possible that the low molecular weight portion is also due to a minor product during polymerization via Wittig reaction. Future works are going to be focus on identification the low molecular weight products of the photo degradation process of LaPPS16 [26].

These results confirm the assumption that the radiation exposure brings about the scission of the polymer chain, being also in agreement with the appearing of narrow lines in ${ }^{1} \mathrm{H}$ NMR spectra due to the presence of small molecules. It is interesting to note in the GPC chromatograms that the population of higher molar mass, in the range of $10^{3}$ to $10^{4}$, did not suffer a significant alteration as compared to that of the lower molecular length. That is, the number of small molecules increased with the irradiation dose, as expected, but that was much more relevant in the lower side of the graph. It has been demonstrated that LaPPS16, as is usual in fully conjugated polymers, has a strong tendency to inter macromolecular aggregation $[29,30]$. In the present case, is possible that the degradation took place preferably in the non-aggregated domains, and that the inter molecular association acted as a kind of protector, hindering to a certain degree the access to the free radicals, which would be captured by the more exposed species. The decrease in polydispersivity with irradiation could be accounted to this effect. Fig. 9 illustrates a mechanistic proposal of the degradation process. In a first step the middle chain carbonyl group is formed as suggested in ref. [23], which in a next step undergoes a clivage through the Norrish mechanism [24] yielding the aldehyde. The last step, a second aldehyde group is formed. In fact the formation of the aromatics aldehyde and the polymer scission shown in Fig. 9 is in good agreement with the appearing of the three narrow lines in the $1 \mathrm{H}$ spectra of the degraded sample of Fig. 7, accounting for the two non-equivalent aromatic protons with chemical shifts in the 7$8 \mathrm{ppm}$ range and the $\pi$ proton at about $10 \mathrm{ppm}$.

The data reported here clearly point out to the application of the results shown, particularly those of Figs. 3 and 4, the potential application of LaPPS16 as active material of blue-light dosimeter for neonatal phototherapy [21,22]. For that, controlling the color changing by adding radicals scavenger or initiator would be highly desirable, in order to provide multipoint measurements and facilitate the device calibration.

\section{Conclusions}

The radiation exposure promotes changes in the absorption and photoluminescence spectra of PPV-type polymers due to chain scission and decrease of conjugation length. It was demonstrated that a hindered phenol type radical scavenger can act as a photodegradation retarder and that a radical initiator as benzoyl peroxide can act as an accelerator for these degradation pathways, without affecting electronic properties of the luminescent
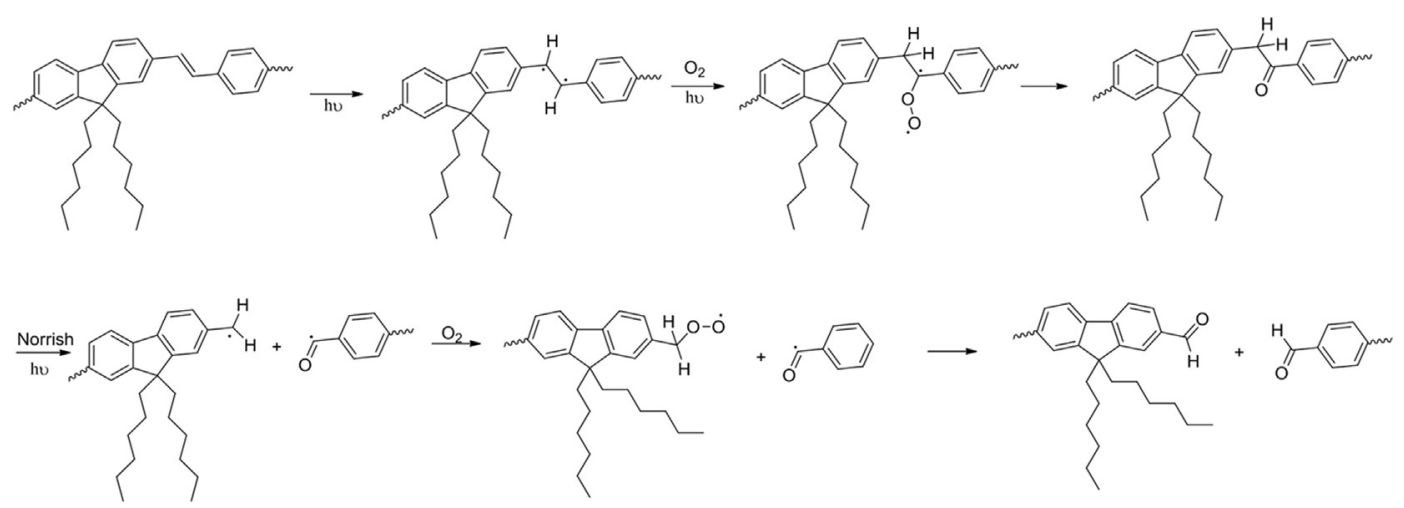

Fig. 9. Mechanistic proposal for the decomposition process of LaPPS16. The formation of the aromatic aldehydes is consistent with the NMR spectra of the degraded sample. 
polymers. The effect was attributed to radical transfer reaction from the polymer backbone to the added compound, where it is stabilized by resonance in the rings. The slowdown of the photo degradation by the presence of the free radical scavenger indicates that free radicals act as an accelerator of the photo-oxidation process. The GPC results suggested that there are preferential sites to degradation giving rise to polymer fragments with the same size. The results reported are of great potential to design proper material to be applied as active parts in the construction of tunable radiation dosimeters for blue-light phototherapy.

\section{Acknowledgments}

This research was made possible by FAPEMIG (Proc. PPM00596-11, PPM-00306-09 and APQ-04124-10), FAPESP (Proc. 2009/18354-8), CAPES, CNPq (Proc. 305646/2010-9 and PDE 200682/2011-3), INEO/CNPq, NEXSeN-FAPITEC- SE/CNPq and REDE NANOBIOMED/CAPES.

\section{References}

[1] C.K. Chiang, C.R. Finger, Y.W. Park, A.J. Heeger, H. Shirakawa, E.J. Louis, C. Graus, A.G. Macdiarmid, Phys. Ver. Lett. 39 (1997) 1098.

[2] L. Akcelrud, Prog. Polym. Sci. 28 (2003) 875-962.

[3] N.S. Sariciftci, Curr. Opin. Solid State Mater. Sci. 4 (1999) 373-378.

[4] R.H. Friend, R.W. Gymer, A.B. Holmes, J.H. Burroughes, R.N. Marks, C. Taliani, D.D.C. Bradley, D.A. Dos Santos, J.L. Bredas, M. Logdlund, W.R. Salaneck, Nature 397 (1999) 121-128.

[5] Z. Bao, Adv. Mater. 12 (2000) 227-230.

[6] L. Torsi, A. Dodabalapur, L.J. Rothberg, A.W.P. Fung, H.E. Katz, Science 272 (1996) 1462-1464.

[7] F. Papadimitrakopoulos, K. Konstadinidis, T.M. Miller, R. Opila, E.A. Chandross, M.E. Galvin, Chem. Mater. 6 (1994) 1563-1568.

[8] J.C. Scott, J.H. Kaufman, P.J. Brock, R. DiPietro, J. Salem, J.A. Goitia, J. Appl. Phys. 79 (1996) 2745-2751.
[9] R.D. Scurlock, B. Wang, P.R. Ogilby, J.R. Sheats, R.L. Clough, J. Am. Chem. Soc. 117 (1995) 10194-10202.

[10] T. Zyung, J. Kim, Appl. Phys. Lett. 67 (1995) 3420-3422.

[11] M. Atreya, S. Lia, E.T. Kanga, K.G. Neoha, Z.H. Mab, K.L. Tanb, W. Huang, Polym. Degrad. Stab. 65 (1999) 287-296.

[12] S. Chambon, M. Manceau, M. Firon, S. Cros, A. Rivaton, J. Gardette, Polymer 49 (2008) 3288-3294.

[13] H.Y. Low, Thin Solid Films 413 (2002) 160-166.

[14] V.N. Bliznyuk, S.A. Carter, J.C. Scott, G. Klärner, R.D. Miller, D.C. Mille, Macromolecules 32 (1999) 361-369.

[15] B. Romero, B. Arredondo, A.L. Alvarez, R. Mallavia, A. Salinas, X. Quintana, J.M. Oton, Solid State Electron. 53 (2009) 211-217.

[16] Y.H. Kim, D.A.V. Bout, Appl. Phys. A 95 (2009) 241-247.

[17] L. Liu, S. Tang, M. Liu, Z. Xie, W. Zhang, P. Lu, M. Hanif, Y. Ma, J. Phys. Chem. B 110 (2006) 13734-13740.

[18] H. Heil, G. Andress, R. Schmechel, H. von Seggern, J. Steiger, K. Bonrad, R. Sprengard, J. Appl. Phys. 97 (2005).

[19] U. Scherf, E.J.W. List, Adv. Mater. 14 (2002) 477-487.

[20] E.J.W. List, R. Guentner, P.S. de Freitas, U. Scherf, Adv. Mater. 14 (2002) 374378.

[21] C.K.B. Vasconcelos, R.F. Bianchi, Sens. Actuators B Chem. 143 (2009) 30-34.

[22] G.R. Ferreira, C.K.B. de Vasconcelos, M.M. Silva, F.A. Santos, J.G. Pires, A.S. Duarte, A.G.C. Bianchi, R.F. Bianchi, Mater. Res. Soc. Symp. Proc. 1209 (2010). P03-03-P03-09.

[23] T. Schimitberger, G.R. Ferreira, L. Akcelrud, M.F. Saraiva, R.F. Bianchi, Sens. Actuators B Chem. 168 (2012) 131-137.

[24] E.A.B. Silva, J.F. Borin, P. Nicolucci, C.F.O. Graeff, T. Ghilardi Netto, R.F. Bianchi, Appl. Phys. Lett. 86 (2005), 902-1-902-3.

[25] B. Ranby, J.F. Rabek, Photodegradation, Photo-oxidation, and Photostabilization of Polymers; Principles and Applications, Wiley-Interscience Publication, London, 1975.

[26] B. Nowacki, E.R. deAzevedo, L. Akcelrud, Polym. Test. 30 (2011) 342-347.

[27] B. Nowacki, E. Iamazaki, A. Cirpan, F. Karasz, T.D.Z. Atvars, L. Akcelrud, Polymer 50 (2009) 6057-6064.

[28] G.R. Ferreira, B. Nowacki, E.R. deAzevedo, L.C. Akcelrud, R.F. Bianchi, Mater. Res. Soc. Symp. Proc. 1286 (2011).

[29] J.R. Tozoni, F.E.G. Guimarães, T.D.Z. Atvars, B. Nowacki, A. Marlleta, L. Akcelrud, T.J. Bonagamba, Eur. Polym. J. 47 (2011) 2259-2265.

[30] J.R. Tozoni, F.E.G. Guimarães, T.D.Z. Atvars, B. Nowacki, A. Marlleta, L. Akcelrud, T.J. Bonagamba, Eur. Polym. J. 45 (2008) 2467-2477. 